\title{
Electropolymerization of aniline monomer and effects of synthesis conditions on the characteristics of synthesized polyaniline thin films
}

\author{
Sanaa El Aggadi *, Nidae Loudiyi, Aicha Chadil, El Abbassi Zoubida and Abderrahim El Hourch \\ Materials, Nanotechnologies and Environment Laboratory, Chemistry Department, Faculty of Sciences, \\ Mohammed V University in Rabat, 4 Avenue Ibn Battouta, BP:1014, Rabat, Morocco
}

\begin{abstract}
Electrochemical polymerization of aniline was carried on platinum $(\mathrm{Pt})$ wire electrode in sulfuric acid $\left(\mathrm{H}_{2} \mathrm{SO}_{4}\right)$ solution by cyclic voltammetry using a conventional three-electrode cell at room temperature $\left(20^{\circ} \mathrm{C}\right)$. The effects on the electrodeposition of the monomer concentration, anodic potential and potential scan rate are discussed. The conductive layer of emeraldine base polyaniline (Pani) was prepared in this work by repeating potential cycling between -0.24 and $0.9 \mathrm{~V} / \mathrm{SCE}$ at $50 \mathrm{mV} / \mathrm{s}$ in $1 \mathrm{M} \mathrm{H}_{2} \mathrm{SO}_{4}$ solution containing $0.1 \mathrm{M}$ aniline monomer.
\end{abstract}

Keywords: Electropolymerization, Polyaniline, Conducting polymer, Cyclic voltammetry.

\section{Introduction}

The use of conductive polymers has made significant progress in the last few decades due to its various applications in energy storage devices ${ }^{1,2}$, biosensors ${ }^{3,4}$, electrocatalysts ${ }^{5,6}$, etc. Polyaniline (Pani) has been at the leading of the global search for commercially viable conductive polymers due to its unique protonic dopability, excellent redox recyclability, chemical stability, variable electrical conductivity, low cost and facile synthesis ?. Therefore, Pani can be used as an electrode material $^{8,9}$, corrosion protection of metals ${ }^{10,11}$, in the manufacture of secondary batteries ${ }^{12}$, in microelectronics ${ }^{13}$ and as an electrochromic material 14-16. Future high-tech applications in the domain of chemical sensors have also been proposed ${ }^{17-19}$. Pani can be prepared by various techniques, namely electrodeposition 20,21, template synthesis 22,23, seeding ${ }^{24}$, and interfacial polymerization ${ }^{25}$. Electrochemical polymerization also called electropolymerization using for this study is a typical method generally used for the synthesis of Pani coating 26,27. Electropolymerization has many
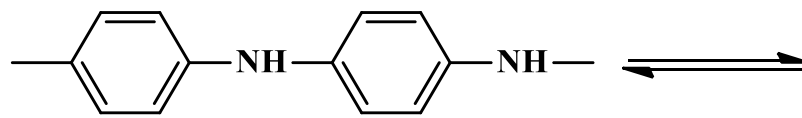

The second redox peak is the emeraldine radical cation to emeraldine and the third redox peak in the range of 0.8 and $1 \mathrm{~V} / \mathrm{SCE}$ is the transformation of advantages related to the direct production of polymers in the doped and undoped state ${ }^{28}$. This synthesis is performed by anodic oxidation of the monomer on inert electrodes such as platinum, carbon, gold and others ${ }^{29,30}$. These polymers can be electrochemically deposited on metal or semiconductor electrodes in film format. The most acceptable start of an electropolymerization mechanism of an aromatic monomer is the formation of a radical cation in two units of the monomer, followed by a dimer formation with the exit of two protons and reconstitution of the aromatic system. The reaction continues with the dimer, and another monomer charged to form a trimer and so on until the polymer is formed. The cyclic voltammograms of Pani deposited on the Pt electrode are characterized by three main pairs of redox peaks. The redox peaks were assigned using the formalism of Pekmez ${ }^{31}$ : The first redox peak appearing between $0.36 \mathrm{~V} / \mathrm{SCE}$ and $0.45 \mathrm{~V} / \mathrm{SCE}$ is the oxidation leucoemeraldine oxidation to leucoemeraldine radical cation interpreted by the following reaction:

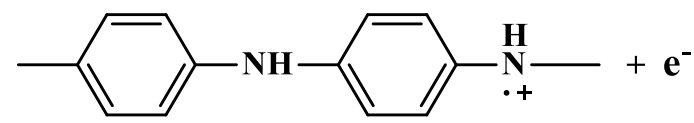

the cation of the pernigraniline radical to pernigraniline as illustrated by the following reaction: 


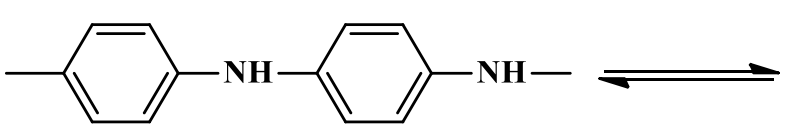

The determinant factor for obtaining a polymer with a high degree of conjugation is the equilibrium of the stability of the monomeric radical cation. The electrical and physicochemical properties of the electrosynthesized material depend strongly on the synthesis conditions. In early studies, Rajapakse and co-workers ${ }^{32}$ reported that polyaniline is non conducting if grown from a medium of $\mathrm{pH}$ above 3 . Pekmez et al. ${ }^{33}$ reported that the optimum monomer concentration is about $100 \mathrm{mM}$ on a Pt surface in acetonitrile $+0.1 \mathrm{M}$ tetrabutylammonium perchlorate solution. Mello Mulato ${ }^{34}$ reported that the monomer concentrations of $0.2 \mathrm{M}$ represent the optimized case in $\mathrm{HCl}(1 \mathrm{M})$ solution on the FTO electrode. Pournaghi-Azar and Habibi ${ }^{35}$ show that the Pani begin to deposit on the $\mathrm{Al}$ electrode in $0.1 \mathrm{M} \mathrm{H}_{2} \mathrm{SO}_{4}$ in aniline solutions higher than $0.35 \mathrm{M}$. Babaiee et al. ${ }^{36}$ reported that aniline fibers with excellent stability and conductivity could be produced on graphite electrode yet, there exists an optimum electropolymerization condition where the scan rate is $25 \mathrm{mV} / \mathrm{s}$, and the switching potential is $1000 \mathrm{mV}$ causing the formation of aniline nanofibers with diameters ranging from 65 to $70 \mathrm{~nm}$ and having good electroactive properties. This study aims to investigate the electropolymerization of aniline (Fig.1) by cyclic voltammetry method using Pt wire as a working electrode in $\mathrm{H}_{2} \mathrm{SO}_{4}(1 \mathrm{M})$ medium. The effects of monomer concentration, anodic potential and potential scan rate are studied.<smiles>Nc1ccccc1</smiles>

Figure 1. Chemical structure of aniline

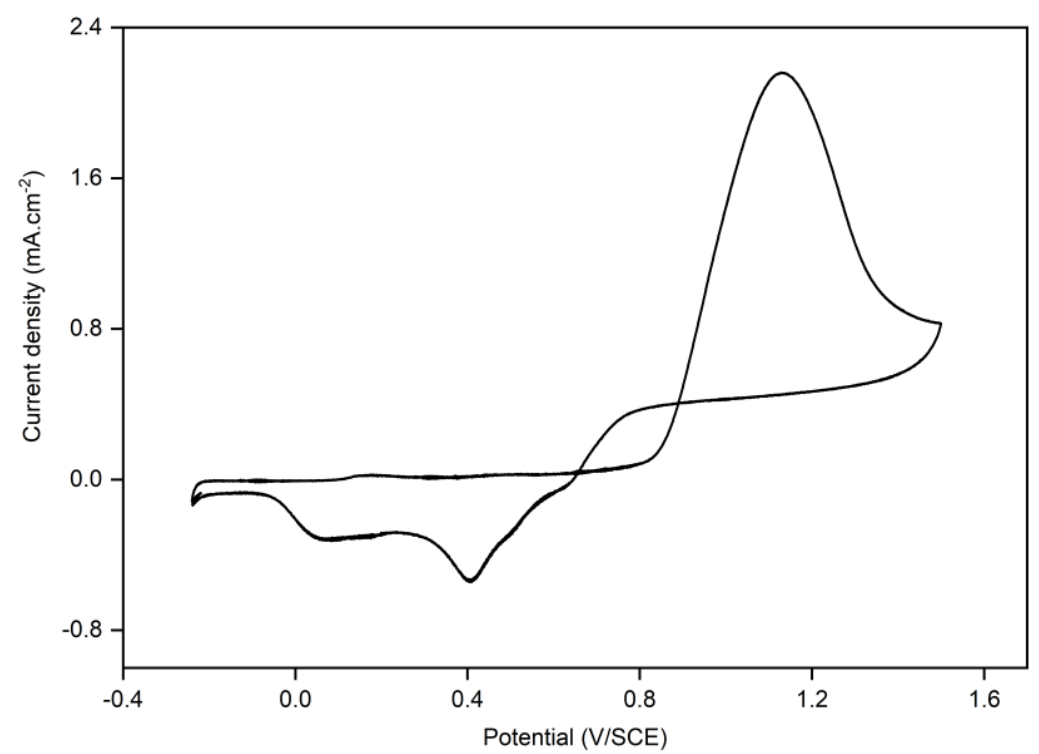

Figure 2. Cyclic voltammogram during electropolymerization of $1 \mathrm{M} \mathrm{H}_{2} \mathrm{SO}_{4}$ solution containing $0.02 \mathrm{M}$ aniline on the $\mathrm{Pt}$ wire electrode at a scan rate of $100 \mathrm{mV} / \mathrm{s}$ 


\section{Results and Discussion}

3.1. Electropolymerization of aniline on the Pt electrode by cyclic voltammetry

Fig. 2 illustrates the first cycle of the voltammogram for a solution of $\mathrm{H}_{2} \mathrm{SO}_{4} 1 \mathrm{M}$, containing $0.02 \mathrm{M}$ aniline monomer on $\mathrm{Pt}$ wire electrode, recorded over a potential range of -0.24 to $1.5 \mathrm{~V} / \mathrm{SCE}$, at a potential scan rate of $100 \mathrm{mV} / \mathrm{s}$.

The voltammogram is characterized by a very significant increase in the anode current from $0.8 \mathrm{~V} / \mathrm{SCE}$ corresponding to the oxidation of the
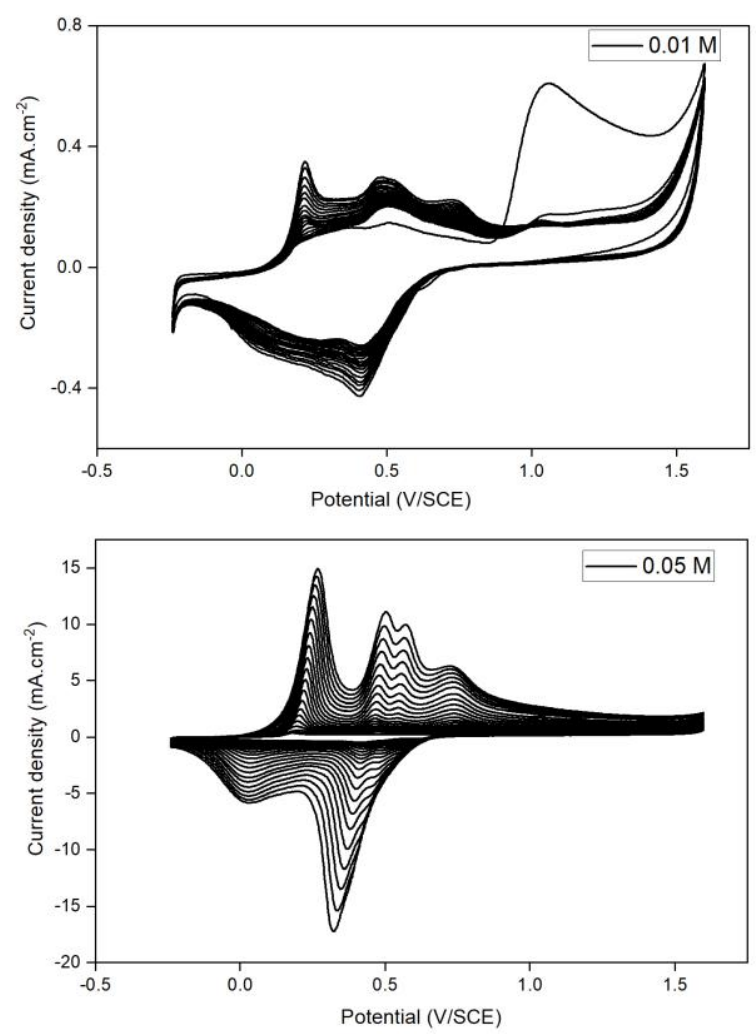

aniline monomer to form the polymer. On the return scan, a reduction wave is observed at about 0.4 V/SCE attributed to the reduction of the aniline formed during its oxidation ${ }^{30}$.

\subsection{Influence of aniline concentration}

Fig.3 shows the cyclic voltammograms recorded during the continuous scan over 20 cycles at 50 $\mathrm{mV} / \mathrm{s}$ potential scan rate between -0.24 and 1.6 V/SCE on Pt wire electrode in $\mathrm{H}_{2} \mathrm{SO}_{4}(1 \mathrm{M})$ solution containing different concentrations of aniline $(0.01$, $0.02,0.05$ and $0.1 \mathrm{M})$.
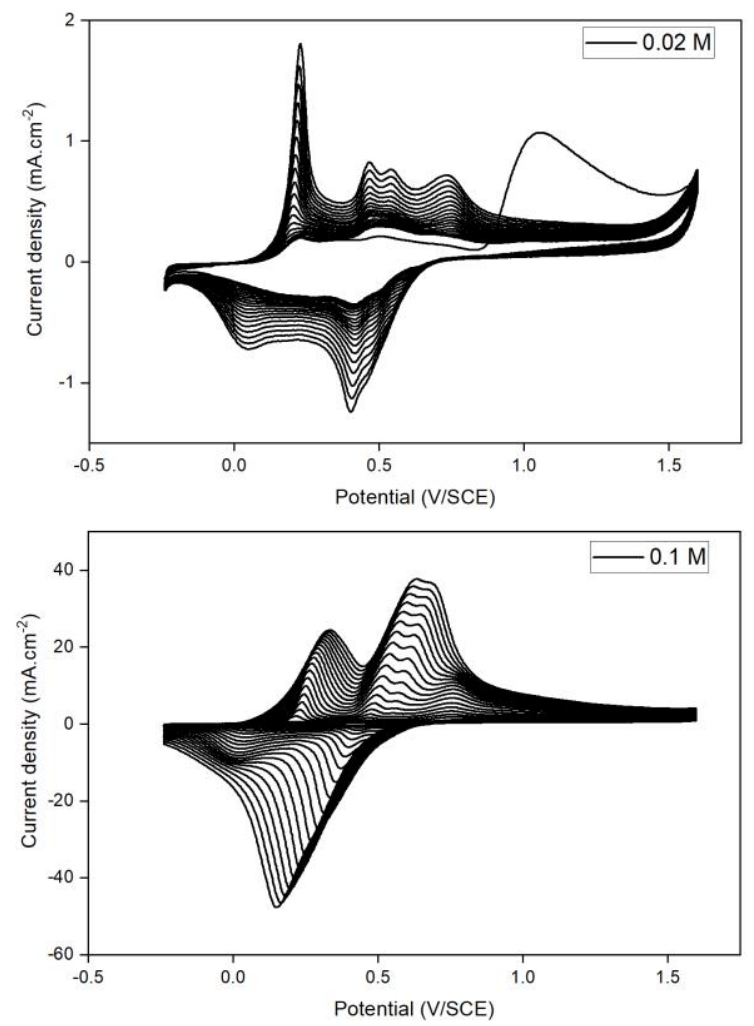

Figure 3. Cyclic voltammograms (20 cycles) of Pani obtained at different concentrations of aniline $(0.01,0.02$, 0.05 and $0.1 \mathrm{M})$ in $\mathrm{H}_{2} \mathrm{SO}_{4}(1 \mathrm{M})$, recorded in a potential range between -0.24 and $1.6 \mathrm{~V} / \mathrm{SCE}$ and at a scan rate of $50 \mathrm{mV} / \mathrm{s}$

According to Fig.3, in all cases, as increasing of cyclic voltammograms number, the oxidation peaks shift to the higher potential values, and the reduction peaks shift to the lower potential values with an increase in current density for all peaks. The intensity of the first peak current density at $0.85 \mathrm{~V} / \mathrm{SCE}$ (oxidation peak of the aniline monomer) decreases and eventually disappears as the number of cycles increases ${ }^{30}$. The cyclic voltammograms show that the current density increases in each successive cycle, which confirms the electrodeposition of Pani films. By simple comparison between the values of the current densities of the first anodic peak of the 20th cycle, we can see that the polymerization rate increases with the concentration of monomers (for a monomer concentration of $0.01 \mathrm{M}$, we have $\mathrm{I}=0.35 \mathrm{~mA} \cdot \mathrm{cm}^{-2}$, for a concentration of $0.02 \mathrm{M}$, we have $\mathrm{I}=1.80 \mathrm{~mA} \cdot \mathrm{cm}^{-2}$, for a concentration of $0.05 \mathrm{M}$, we have $\mathrm{I}=14.90 \mathrm{~mA} \cdot \mathrm{cm}^{-2}$, while for a monomer concentration of $0.1 \mathrm{M}$, we have $\left.\mathrm{I}=24.45 \mathrm{~mA} \cdot \mathrm{cm}^{-2}\right)$. Polymerization under cyclic voltammetry conditions provided information about the growth of the film. Oxidation of the monomer began at $0.85 \mathrm{~V}$ and eventually disappeared as the number of cycles increases. For the three low aniline concentrations $(0.01,0.02$ and $0.05 \mathrm{M})$, we can see the presence of four redox peaks. The first redox peak at around $0.2 \mathrm{~V} / \mathrm{SCE}$ corresponded to the first step of oxidation of the species $\mathrm{HN}-\mathrm{R}-\mathrm{NH}\left(\mathrm{R}: \mathrm{C}_{6} \mathrm{H}_{4}\right)$ in the main chain to a cation radical or polaron system $\mathrm{HN}-\mathrm{R}-\mathrm{NH}^{+}$. The cation radical was then oxidized, practically at the same potential, to the dication or bipolaron $\mathrm{HN}^{+}=\mathrm{R}=\mathrm{NH}^{+}$. The middle redox peaks (second and third peaks) at around $0.5 \mathrm{~V} / \mathrm{SCE}$ are attributed to the oxidation of intermediate compounds or secondary oxidation products. The fourth redox peak observed at around $0.75 \mathrm{~V} / \mathrm{SCE}$ related to the bipolaron redox ${ }^{30,37}$. For 
the aniline concentration of $0.1 \mathrm{M}$, we can see the presence of the three first redox peaks mentioned above. The resulting voltammograms indicate that only Pani formed in the medium with the highest aniline concentration $(0.1 \mathrm{M})$ has three identified redox waves with currents associated with redox transitions between these different species significantly higher compared to films made in more diluted monomer solutions ${ }^{34,38}$.
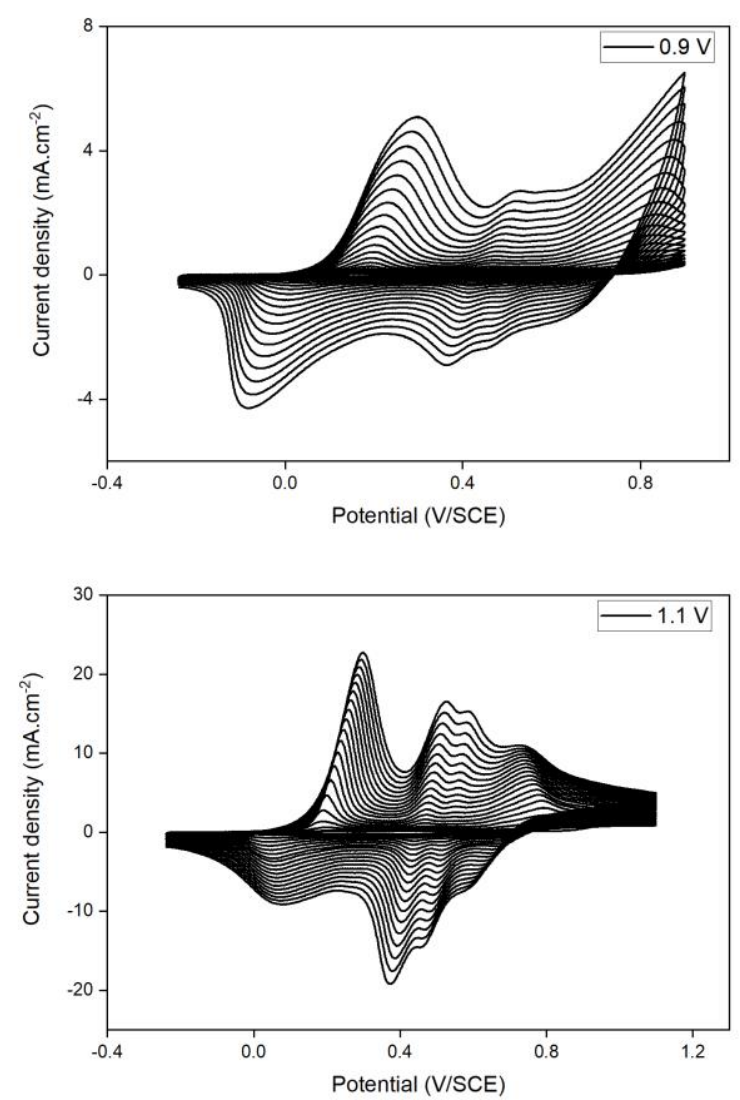

\subsection{Influence of the anodic potential}

The electropolymerization of aniline $(0.1 \mathrm{M})$ in $\mathrm{H}_{2} \mathrm{SO}_{4}(1 \mathrm{M})$ by cyclic voltammetry at a potential scan rate of $50 \mathrm{mV} / \mathrm{s}$ on $\mathrm{Pt}$ wire electrode for different anode potential values ranging from the same starting potential $(-0.24 \mathrm{~V} / \mathrm{SCE})$ to gradually increased anode return potentials, is shown in Fig.4.
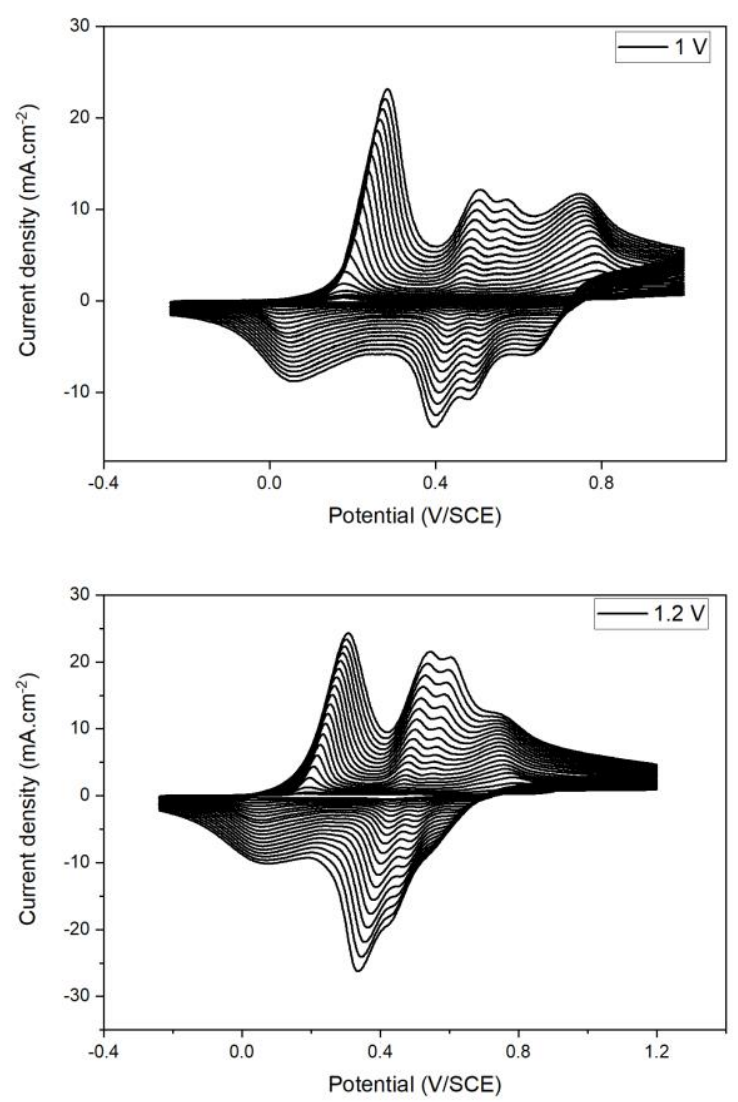

Figure 4. Cyclic voltammograms (20 cycles) during electropolymerization of aniline on the Pt wire electrode in $1 \mathrm{M} \mathrm{H}_{2} \mathrm{SO}_{4}$ solution containing $0.1 \mathrm{M}$ aniline at a scan rate of $50 \mathrm{mV} / \mathrm{s}$

As illustrated in Fig.4, for the four cases, the oxidation peaks shift to the anodic direction, and the reduction peaks shift to the cathodic direction with an increase in current density for all anodic peaks with the increase of the number of cycles. The electrochemical behaviour indicates that the conductive polymer is formed and that a polymer deposit is visible. The anodic return potential has a significant influence on the electrochemical stability of Pani films. In the case of a minimum return potential of $0.9 \mathrm{~V} / \mathrm{SCE}$, only one pair of redox peaks are present in the cyclic voltammograms corresponding to the transition value of leucoemeraldine. For the three return potential voltammograms of $1,1.1$ and $1.2 \mathrm{~V} / \mathrm{SCE}$ have four pairs of redox peaks that appear to be more marked in cyclic voltammograms (i.e. other forms of aniline that are less conductive). During the oxidation process, the aniline monomer exhibits an electrochromic behaviour, being yellow at low potential value and passing through green and blue to black at higher potentials ${ }^{39-41}$.

\subsection{Influence of the potential scan rate}

We plotted the cyclic voltammograms of a $1 \mathrm{M}$ $\mathrm{H}_{2} \mathrm{SO}_{4}$ solution containing $0.1 \mathrm{M}$ aniline, recorded in a potential range of -0.24 to $0.9 \mathrm{~V} / \mathrm{SCE}$ for different potential scan rate from 10 to $100 \mathrm{mV} / \mathrm{s}$ (Fig.5). 

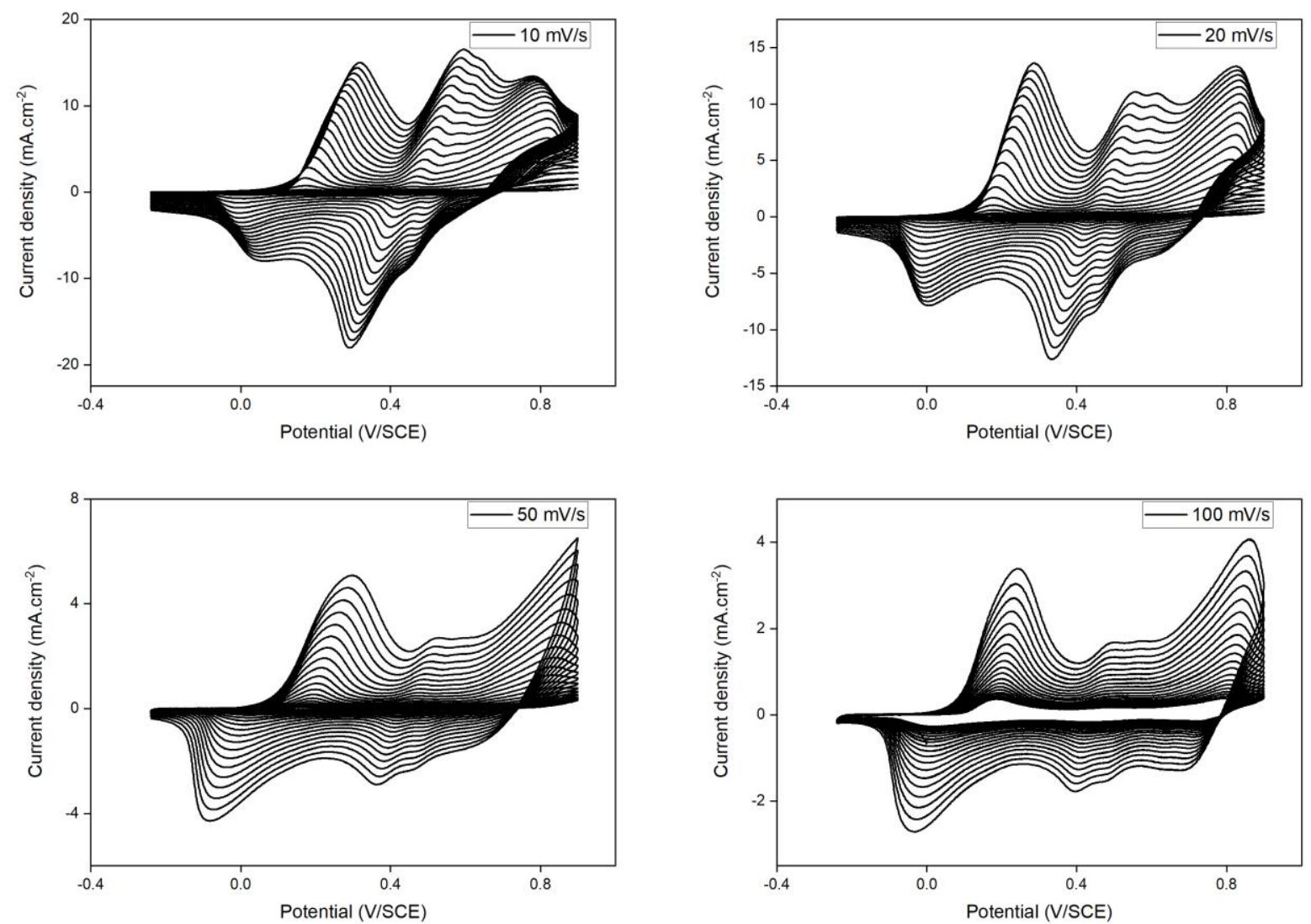

Figure 5. Cyclic voltammograms (20 cycles) during electropolymerization of aniline on the Pt wire electrode in $1 \mathrm{M} \mathrm{H}_{2} \mathrm{SO}_{4}$ solution containing $0.1 \mathrm{M}$ aniline at different potential scan rate (from 10 to $100 \mathrm{mV} / \mathrm{s}$ )

As the scan rate increases, the oxidation peaks shift slightly to a more positive potential, while the reduction peaks shift to a more negative potential. For the potential scan rate of $50 \mathrm{mV} / \mathrm{s}$ only one pair of redox peaks is present in the cyclic voltammograms corresponding to the oxidation of

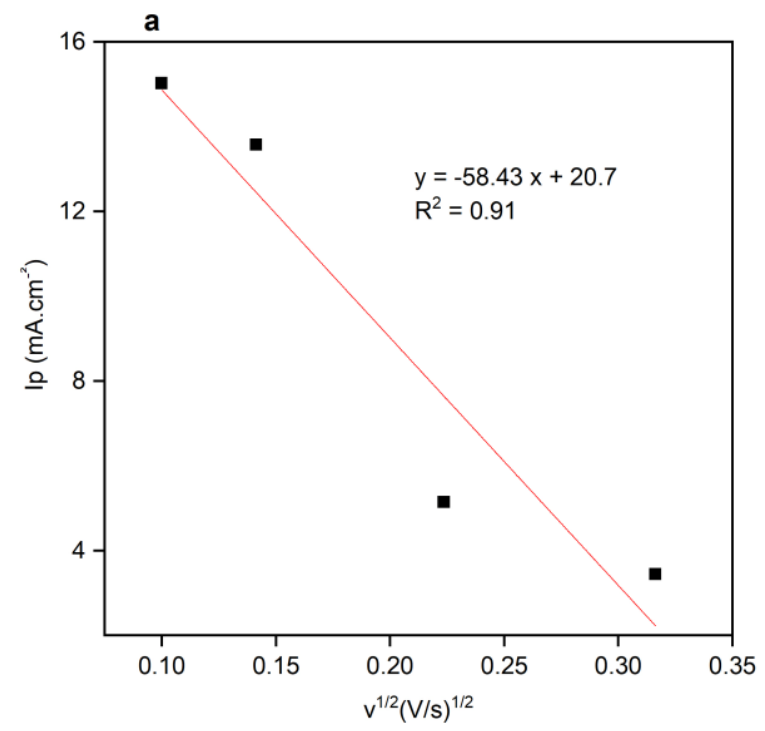

leucoemeraldine to emeraldine. On the other hand, the other scans rates $(10,20$ and $100 \mathrm{mV} / \mathrm{s})$ have three pairs of redox peaks, i.e. other forms of less conductive aniline. It can be seen that the current density of the oxidation peaks decreases with increasing potential scan rate ${ }^{42}$.

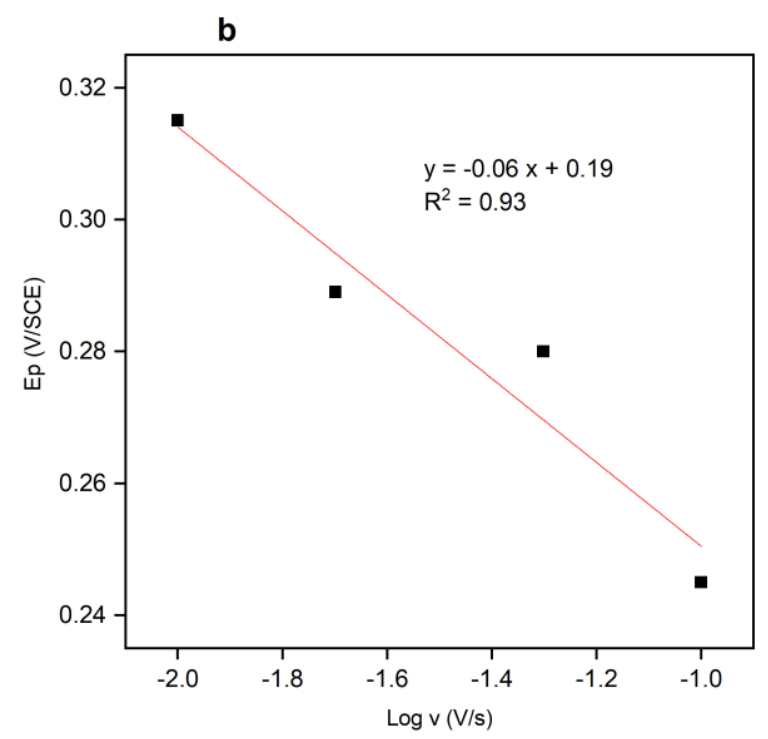

Figure 6. a-Dependence of the oxidation peak current on the square root of the potential scan rate. bDependence of the oxidation peak potential on log potential scan rate 
The linear variation of the anode current peak (last cycles) with the square root of the potential scan rate (Fig.6a) shows that the electrochemical reaction at the electrode-electrolyte interface is controlled by the diffusion process. On the other hand, there is a significant increase in the difference between the oxidation peak potential and the reduction peak potential associated with a given redox couple when the potential scan rate increases. This reflects a slight decrease in the reversibility of redox couples for highest potential scans rates (Fig.6b).

\subsection{Study of the Pani films in $\mathrm{H}_{2} \mathrm{SO}_{4}$}

Pani films were prepared on the $\mathrm{Pt}$ wire working electrode by the cyclic voltammetry within the potential of $-0.24 \mathrm{~V} / \mathrm{SCE}$ to $0.9 \mathrm{~V} / \mathrm{SCE}$ for 10 cycles in a solution containing $0.1 \mathrm{M}$ aniline and $1 \mathrm{M}$ sulfuric acid. Moreover, the potential scan rate of electropolymerization was set at $50 \mathrm{mV} / \mathrm{s}$. After the electropolymerization of the aniline, the electrodeposited Pani electrode is cleaned several times with deionized water to remove the rest of the aniline solution and then activated in an $\mathrm{H}_{2} \mathrm{SO}_{4}$ solution, then we plotted the cyclic voltammograms of Pani modified electrode in a $1 \mathrm{M} \mathrm{H}_{2} \mathrm{SO}_{4}$ solution without aniline, recorded in a potential range of -0.24 to $1.0 \mathrm{~V} / \mathrm{SCE}$ at a potential scan rate of $10 \mathrm{mV} / \mathrm{s}$ (Fig.7).

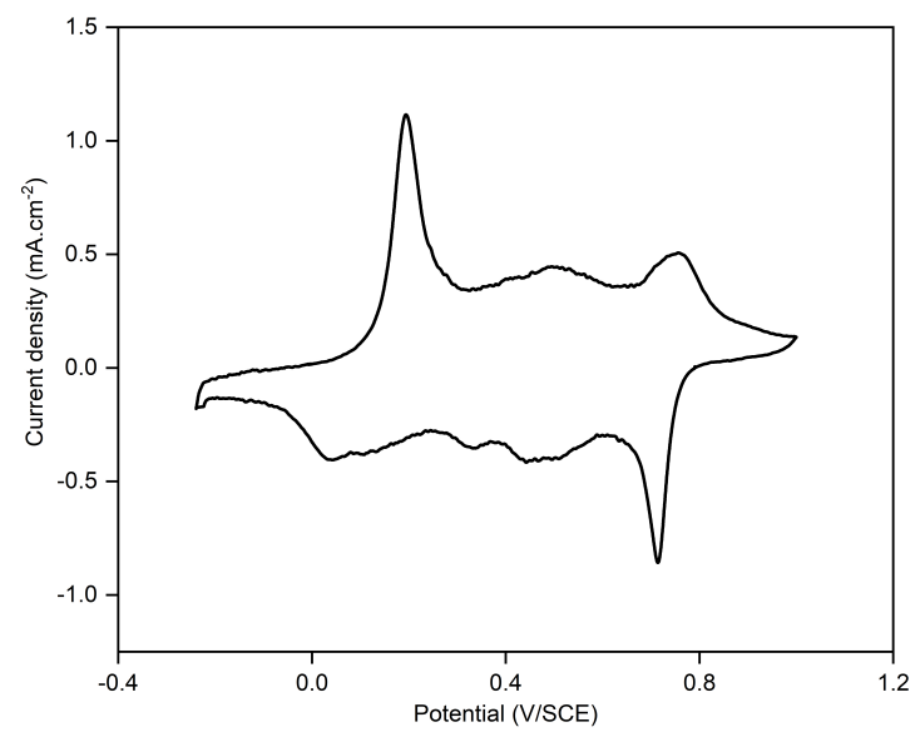

Figure 7. Cyclic voltammogram at Pt wire electrode modified with a Pani film in $1 \mathrm{M} \mathrm{H}_{2} \mathrm{SO}_{4}$ solution, obtained at a potential scan rate of $10 \mathrm{mV} / \mathrm{s}$ and between -0.24 and $1 \mathrm{~V} / \mathrm{SCE}$

The electrode modified by a Pani film placed in $\mathrm{H}_{2} \mathrm{SO}_{4}$ solution without monomer has the same electrochemical behavior as that observed in $\mathrm{H}_{2} \mathrm{SO}_{4}$ solution in the presence of monomer at the end of electroplating. The major features of this curve are the appearance of two pairs of peaks corresponding to the oxidation-reduction transitions of polyaniline, namely the transition from leucoemeraldine to emeraldine and from emeraldine to pernigraniline ${ }^{43}$. The peaks in the middle are caused by degradation products. These peaks are attributed to the presence of phenazine cycles. The formation of phenazine structures in the polymer is attributed to the electropolymerization of high potential aniline, which is related to the reaction of aniline nitrenium cations in ortho position on another ring or to crosslinking between two Pani chains ${ }^{44}$.

\section{Conclusion}

Pani films were electrochemically deposited by cyclic voltammetry of $\mathrm{Pt}$ wire electrode in $\mathrm{H}_{2} \mathrm{SO}_{4}$ solution contains aniline with varying aniline concentration, anodic potential and potential scan rate. Aniline electropolymerization results show that the rate of polymerization increases with increasing monomer concentration. The aniline concentration of $0.1 \mathrm{M}$, has three identified first redox waves with significantly higher currents densities for redox reactions between these different species for films produced in more dilute monomer solutions. The voltammograms of the anodic return potential of $0.9 \mathrm{~V} / \mathrm{SCE}$ and the potential scan rate of $50 \mathrm{mV} / \mathrm{s}$, have a single redox peak, corresponding to the oxidation of leucoemeraldine to emeraldine conductive layer of Pani. A linear relationship between the density of current and the square root of the potential scan rate was observed, which indicates that the electrochemical reaction at the electrodeelectrolyte interface is controlled by the diffusion process.

\section{References}

1- J. Kim, J. Lee, J. You, M.S. Park, M.S. Al Hossain, Y. Yamauchi, J.H. Kim, Conductive polymers for next-generation energy storage systems: Recent progress and new functions, Mater. Horizons., 2016, 3, 517-535.

2- A.M. Bryan, L.M. Santino, Y. Lu, S. Acharya, 
J.M. D’Arcy, Conducting Polymers for Pseudocapacitive Energy Storage, Chem. Mater., 2016, 28, 5989-5998.

3- Y. Liu, A.P.F. Turner, M. Zhao, W.C. Mak, Processable enzyme-hybrid conductive polymer composites for electrochemical biosensing, Biosens. Bioelectron., 2018, 100, 374-381.

4- R.K. Pal, S. Pradhan, L. Narayanan, V.K. Yadavalli, Micropatterned conductive polymer biosensors on flexible PDMS films, Sensors Actuators, B Chem., 2018, 259, 498-504.

5- Y.-T. Dong, J.-X. Feng, G.-R. Li, Transition Metal Ion-Induced High Electrocatalytic Performance of Conducting Polymer for Oxygen and Hydrogen Evolution Reactions, Macromol. Chem. Phys., 2017, 218, 1700359.

6- M. Salado, S. Kazim, S. Ahmad, Conductive Polymer Based Electrocatalysts for I-Mediated Dye-Sensitized Solar Cells, Count. Electrodes Dye. Perovskite Sol. Cells, Wiley-VCH Verlag GmbH \& Co. KGaA, Weinheim, Germany, 2018, 177-196. https://doi.org/10.1002/9783527813636.ch8.

7- P.C. Maity, Polyaniline: Synthesis and Natural Nanocomposites, Doctoral dissertation, Indian Institute of Technology Hyderabad, 2016. Related URLs to Google Scholar: http://raiith.iith.ac.in/2718/

8- M.A. Smirnov, E.V. Tarasova, V.K. Vorobiov, I.A. Kasatkin, V. Mikli, M.P. Sokolova, N. V. Bobrova, V. Vassiljeva, A. Krumme, A.V. Yakimanskiy, Electroconductive fibrous mat prepared by electrospinning of polyacrylamide-gpolyaniline copolymers as electrode material for supercapacitors, J. Mater. Sci., 2019, 54, 4859-4873.

9- S. Chen, B. Liu, X. Zhang, F. Chen, H. Shi, C. $\mathrm{Hu}, \mathrm{J}$. Chen, Growth of polyaniline on $\mathrm{TiO}_{2}$ tetragonal prism arrays as electrode materials for supercapacitor, Electrochim. Acta., 2019, 300, 373-379.

10-P.T. Bertuoli, A.F. Baldissera, A.J. Zattera, C.A. Ferreira, C. Alemán, E. Armelin, Polyaniline coated core-shell polyacrylates: Control of film formation and coating application for corrosion protection, Prog. Org. Coatings., 2019, 128, 40-51.

11-A. Merz, M. Uebel, M. Rohwerder, The protection zone: A long-range corrosion protection mechanism around conducting polymer particles in composite coatings: Part I. polyaniline and polypyrrole, J. Electrochem. Soc., 2019, 166, C304-C313.

12-A. Rochliadi, S.A. Akbar, V. Suendo, Polyaniline/Zn as a secondary battery for electric vehicle base on energy return factor, Proc. Jt. Int. Conf. Electr. Veh. Technol. Ind. Mech. Electr. Chem. Eng., 2015, 353-358.

13-J. Li, L. Liu, D. Zhang, D. Yang, J. Guo, J. Wei, Fabrication of polyaniline/silver nanoparticles/multi-walled carbon nanotubes composites for flexible microelectronic circuits, Synth. Met., 2014, 192, 15-22.

14-S. Ranjbar, M.A.F. Nejad, C. Parolo, S. Shahrokhian, A. Merkoçi, Smart Chip for Visual Detection of Bacteria Using the Electrochromic Properties of Polyaniline, Anal. Chem., 2019, 91, 14960-14966.

15-Y. Zhao, S. Zhang, F. Hu, J. Li, H. Chen, J. Lin, B. Yan, Y. Gu, S. Chen, Electrochromic polyaniline/aramid nanofiber composites with enhanced cycling stability and film-forming property, J. Mater. Sci. Mater. Electron., 2019, 30, 12718-12728.

16-S. Zhang, S. Chen, F. Yang, F. Hu, B. Yan, Y. Gu, H. Jiang, Y. Cao, M. Xiang, Highperformance electrochromic device based on novel polyaniline nanofibers wrapped antimonydoped tin oxide/ $\mathrm{TiO}_{2}$ nanorods, Org. Electron., 2019, 65, 341-348.

17-A.L. Winck, J.C.V. Dos Santos, D.M. Lenz, D.M. Tedesco, Development and characterization of gas sensors using thin films of polyaniline as an active layer, Rev. Mater, 2018, 23. http://dx.doi.org/10.1590/s1517707620180004.0593.

18-L.O. Mandú, A. Batagin-Neto, Chemical sensors based on $\mathrm{N}$-substituted polyaniline derivatives: reactivity and adsorption studies via electronic structure calculations, J. Mol. Model., 2018, 24, 157.

19-S.B. Kulkarni, Y.H. Navale, S.T. Navale, F.J. Stadler, N.S. Ramgir, V.B. Patil, Hybrid polyaniline- $\mathrm{WO}_{3}$ flexible sensor: A room temperature competence towards $\mathrm{NH}_{3}$ gas, Sensors Actuators, B Chem., 2019, 288, 279-288.

20- N. Hui, F. Chai, P. Lin, Z. Song, X. Sun, Y. Li, S. Niu, X. Luo, Electrodeposited Conducting Polyaniline Nanowire Arrays Aligned on Carbon Nanotubes Network for High-Performance Supercapacitors and Sensors, Electrochim. Acta., 2016, 199, 234-241.

21-S. Gutić, M. Cacan, F. Korać, Electrodeposition of polyaniline films on stainless steel and their voltammetric behavior in corrosive environments, Bull Chem Technol Bosn Herz., 2017, 48, 45-50.

22-Y. Kaykha, M. Rafizadeh, Template synthesis of fibrillar polyaniline complex using a degradable polyelectrolyte, Mater. Chem. Phys, 2019, 229, 98-105.

23-L.S. Rego, J.L.S. Antonio, C.H.B. Silva, M.M. Nobrega, M.L.A. Temperini, R.M. Torresi, S.I. Córdoba de Torresi, Electrochemical template synthesis of adherent polyaniline thin films with tubular structure, J. Solid State Electrochem., 2016, 20, 983-991.

24-B. Gao, H. Zhou, J. Yang, Hierarchically porous carbons derived from polyaniline by "nanotube seeding" for high-performance ionic liquid-based supercapacitors, J. Mater. Chem. A., 2017, 5, 524-528. 
25-F.F. Fang, Y.Z. Dong, H.J. Choi, Effect of oxidants on the morphology of interfacial polymerized polyaniline nanofibers and their electrorheological response, Polymer, 2018, 158, 176-182.

26-Y. Li, Y. Yi, W. Yang, X. Liu, Y. Li, W. Wang, Effect of Different Electrode Materials on the Electropolymerization Process of Aniline in Nitric Acid Media, J. Electron. Mater., 2017, 46, 1324-1330.

27-F. Akrami, L. Marinelli, R. West, Electropolymerization of Polyaniline in the Presence of Ferricyanide, Creat. Act. Res. Day CARD., 2019.

28-S. Schneider, M. Füser, M. Bolte, A. Terfort, Self-assembled monolayers of aromatic pyrrole derivatives: Electropolymerization and electrocopolymerization with pyrrole, Electrochim. Acta., 2017, 246, 853-863.

29-R. Mažeikiená, G. Niaura, A. Malinauskas, In situ time-resolved Raman spectroelectrochemical study of aniline polymerization at platinum and gold electrodes, Chemija., 2018, 29, 81-88.

30-A. Palma-Cando, I. Rendón-Enríquez, M. Tausch, U. Scherf, Thin Functional Polymer Films by Electropolymerization, Nanomaterials, 2019, 9, 1125.

31-E.I. Iwuoha, S.E. Mavundla, V.S. Somerset, L.F. Petrik, M.J. Klink, M. Sekota, P. Bakers, Electrochemical and Spectroscopic Properties of Fly Ash-Polyaniline Matrix Nanorod Composites, Microchim. Acta., 2006, 155, 453-458.

32-R.M.G. Rajapakse, L.P.P. Lankeshwara, M.A. Careem, Factors affecting the electropolymerization of aniline from aqueous solutions, Institute of Electrical and Electronics Engineers, 2005, 256-256.

33-N. Pekmez, K. Pekmez, M. Arca, A. Yildiz, The effect of monomer and acid concentrations on electrochemical polyaniline formation in acetonitrile, J. Electroanal. Chem., 1993, 353, 237-246.

34-H.J.N.P.D. Mello, M. Mulato, Effect of aniline monomer concentration on PANI electropolymerization process and its influence for applications in chemical sensors, Synth. Met., 2018, 239, 66-70.

35-M.H. Pournaghi-Azar, B. Habibi, Electropolymerization of aniline in acid media on the bare and chemically pre-treated aluminum electrodes. Comparative characterization of the polyaniline deposited electrodes, Electrochim. Acta., 2007, 52, 4222-4230.

36-M. Babaiee, M. Pakshir, B. Hashemi, Effects of potentiodynamic electropolymerization parameters on electrochemical properties and morphology of fabricated PANI nanofiber/graphite electrode, Synth. Met., 2015, 199, 110-120.

37-E. De Robertis, R.S. Neves, A.J. Motheo, Electropolymerization studies of PAni/(poly)luminol over platinum electrodes, Mol. Cryst. Liq. Cryst., 2008, 484, 322.

38-S. Rahmadhani, H. Setiyanto, M.A. Zulfikar, Electropolymerized of aniline as a new molecularly imprinted polymer for determination of phenol: A study for phenol sensor, Int. Semin. Sensors, Instrumentation, Meas. Metrol., Institute of Electrical and Electronics Engineers Inc., 2017, 124-128.

39-L. Vacareanu, A.M. Catargiu, M. Grigoras, An electrochemical study of two self-dopable watersoluble aniline derivatives: Electrochemical deposition of copolymers, J. Anal. Methods Chem., 2012. https://doi.org/10.1155/2012/737013.

40-T. Kobayashi, H. Yoneyama, H. Tamura, Electrochemical reactions concerned with electrochromism of polyaniline film-coated electrodes, J. Electroanal. Chem., 1984, 177, 281-291.

41-B. Wang, J. Tang, F. Wang, Electrochemical polymerization of aniline, Synth. Met., 1987, 18, 323-328.

42-B. Rakovska, A. Valiūnienè, A. Malinauskas, V. Kubilius, R. Valiūnas, Electrochemical formation of polyaniline on $\mathrm{Ti}$ and electrochemically oxidized Ti electrodes, The Electrochemical Society, 2012, 37, 2314-2314.

43-O.E. Fayemi, A.S. Adekunle, E.E. Ebenso, Electrochemical detection of phenanthrene using nickel oxide doped PANI nanofiber-based modified electrodes, Journal Nanomater, 2016, 2016. https://doi.org/10.1155/2016/9614897.

44-H. Tang, Y. Ding, C. Zang, J. Gu, Q. Shen, J. Kan, Effect of Temperature on Electrochemical Degradation of Polyaniline, Int. J. Electrochem. Sci., 2014, 12, 7239-7252. 